\title{
Heavy metals pollution of a solid waste landfill
}

\author{
Tatiana K. Blokhina ${ }^{1, *}$, and Oksana A. Karpenko ${ }^{1}$ \\ ${ }^{1}$ Economics department, Peoples Friendship University of Russia (RUDN University) \\ 6, Miklukho-Maklaya st., Moscow, 117198, Russian Federation
}

\begin{abstract}
The article is devoted to the problems of pollution of a solid waste landfill. Heavy metals are not only pollutants, but also natural micro components of soils. Their contents are caused by the mechanical and chemical composition of the soil breed and also by the nature of soil creating processes. In our article we will estimate extent of pollution by heavy metals of the solid waste landfill "Kuchino" which is located in $7 \mathrm{~km}$ to the east from the Moscow. The total area of land branches is $-54,5001$ hectares. The analysis of the importance of polyelement pollution of soils of a zone of influence of Kuchino solid waste landfill showed that more than $50 \%$ of the surveyed points are characterized by the admissible level of total accumulation, dangerous category is noted in $8 \%$ of the tested positions, extra dangerous - in 37\%. The authors proposed the construction of the system of a beam drainage on solid waste landfill is one of possible ways of decrease in negative impact of heavy metals on the environment.
\end{abstract}

\section{Introduction}

Heavy metals belong to priority pollutants, there is a special control of these pollutants in all environments. The special criteria of heavy metals different characteristics are used: the atomic mass, density, toxicity, prevalence in the environment, degree of the involvement into natural and technogenic cycles. In some cases we use a definition of heavy metals while using the elements relating to fragile (bismuth) or to metalloids (arsenic). Prominent scientists identified more than 40 heavy metals with atomic mass over 50 atomic units, others consider heavy metals as metals with a density more than $80 \mathrm{~g} / \mathrm{cm}$ (lead, copper, nickel, cadmium, cobalt, tin, selenium, bismuth, mercury) [1]. The researches by Kodom [1] were devoted to problems of a research of content of heavy metals in the soil. Mmlova et. al. [2] made an assessment of heavy metal pollution in soils along major roadside areas, Grzebisz et. al. [3] made a geochemical assessment of urban soils. Dragović et. al. [4] studied the heavy metals distribution in soils. In our research we made an attempt to study impurity degree heavy metals of the reclaimed solid waste landfill.

Heavy metals are not only pollutants, but also natural microcomponents of soils. Their contents are caused by the mechanical and chemical composition of the soil breed and also by the nature of soil creating processes. The background maintenance of these elements

\footnotetext{
* Corresponding author: blokhina_tk@rudn.ru
} 
corresponds to their natural concentration in various soil and climatic zones which are not under any anthropogenic influence. The anthropogenic processes elements are always in the soil and the question of background maintenance can be considered only conditionally as this total background has both a natural and anthropogenic component.

\section{Materials and methods}

Heavy metals in Russia on degree of danger are subdivided into three classes:

I class: arsenic, cadmium, mercury, lead, zinc, fluorine, 3,4-benz (and) pyrene.

I class: pine forest, cobalt, nickel, molybdenum, copper, antimony, chrome.

II class: Barium, vanadium, tungsten, manganese, strontium/

The standard list of chemical researches of soils includes determination of content:

- heavy metals 1 and 2 of a class of danger (lead, cadmium, zinc, mercury, copper, nickel and arsenic).

- 3,4-benzpyrene and oil products.

The expanded list of researches is carried out including certain specific sources of soils pollution and by definition of fuller nomenclature of the polluting chemicals. The choice of indicators depends on estimated composition of pollutants taking into account character of a source of pollution of soils [5].

The metals coming from the polluted atmosphere to the soil are fixed by processes of adsorption, sedimentation, coagulation, interpackage absorption by clay minerals. The arriving compounds of heavy metals can collapse soil organic acids, be occluded by the SAC (soil absorbing complex) components or under certain soil conditions to be besieged in the form of insoluble salts [6]. However they pass a solution phase in which they are the most mobile.

The main role in the soil is played by organic substance, clay minerals and hydroxides of iron and manganese [7]. At first metals are occluded generally nonspecific, but over time they strengthen. It is expressed in reduction of maintenance of water-soluble and fragile forms. It is promoted by frequent change of the modes of moistening and siccation of soils. Heavy metals are immobilized and pass into nontoxical forms in the course of sorption by the soil, some of them enter a crystal lattice of aluminosilicates. For example, technogenic lead and copper are transformed in the soil to less mobile, and zinc and cadmium - to more mobile.

Organic substance of soils fixes heavy metals by specific and nonspecific adsorption. Level of durability of communications of heavy metals with organic substance depends also on a metal. So, copper communicates stronger, than zinc and cadmium.

The communications between heavy metals and clay minerals have the exchange and not exchange forms. Zinc has the greatest affinity to the mineral components, copper and lead have the smallest one. Therefore the oozy fraction of soils is enriched with zinc and grown by copper and lead in comparison with all soil components.

In the lower soil horizons the main role in fixing of heavy metals is played by oxides and hydroxides of iron, manganese and aluminum. Their fixing mechanism is adsorption or sedimentation. Some oxides and hydroxides have high affinity to concrete heavy metal. Many heavy metals become inactive in the soils with iron, because of processes of occlusion.

Growth $\mathrm{pH}$ leads to increase in durability of compounds of heavy metals with soil components. A number of adsorption is generally maintained: lead > copper > zinc > cadmium. The last one is occluded most actively, but other metals lowers cadmium sorption at 2-14 times; the main competitor is zinc which is also poorly fixed in the soil because of affinity with the mineral components and low-molecular organic chemistry. The main way 
of fixing of heavy metals is nonspecific adsorption. The degree of their mobility can be more than $63 \%$ [8].

Lead, mercury, cadmium and some other heavy metals are well occluded in the top layers (several centimeters) of the humic horizon of loamy soils. Their migration on a profile and carrying out of limits of a soil profile are insignificant. In soils of light particle size distribution, sour and grown poor by a humus, processes of migration of these heavy metals increase. Copper and zinc are less toxic, but they are more mobile, than lead and cadmium. The migration ability goes down at the increased content of organic substance and weighting of particle size distribution of soils.

The oxidation-reduction conditions and acidity have impact on behavior of heavy metals in the soil. The migration ability of copper, nickel, cobalt and zinc in the recovery environment decreases in 1-2 times in comparison with oxidizing; in acidic environment the majority of metals are more mobile. Adverse physical and chemical properties of podsolic and cespitose and podsolic soils (the increased acidity and contents of ions of aluminum) promote transition of heavy metals to biological fabrics, increase in migration of heavy metals, deterioration in activity of nitrifying and bacteria which often reduce fertility of the soil [9]. Radial and lateral migration of heavy metals is caused by migration as a part of water-soluble organic compounds. The increased accumulation of heavy metals can be observed in soils of transaccumulative positions. Therefore, transaccumulative landscapes of zones of influence of the enterprises are more exposed to technogenic influence. According to researches the semi-removal period is of 70-510 years for anthropogenically introduced zinc, cadmium - 13-110 years, copper of 310-1500 years, lead - 740-5900 years. In our article we will estimate extent of pollution by heavy metals of the solid waste landfill "Kuchino" which is located in $7 \mathrm{~km}$ to the east from the Moscow. The total area of land branches is $-54,5001$ hectares. The volume of the waste buried in the ground by results of assessment which is carried out within engineering researches is 20,3 million tons. Now the technogenic embankment of irregular shape is created on the site above a natural surface. At the time of work on recultivation the power of bulk soil on the top platform was 2.0-3.0 m. The maximum marks of an embankment of waste are 187-189 m. Height of an embankment of waste over a natural relief is 50-57 meters. The altitude of an embankment of waste (taking into account depth of earlier fulfilled pit) reaches $60-64 \mathrm{~m}$. The total area of land branch under the planned activity is 54,5001 hectares. Now the territory is occupied with a landfill of the closed solid waste landfill [10]. The natural matrix of a soil cover of the territory consists from the cespitose and podsolic soils of light particle size distribution with $20-30 \%$ of marsh and podsolic soils (cespitose podzols gley and peat podzols gley) and up to $10-30 \%$ of marsh soils which are in bad conditions. Alluvial soils are dated for floodplains of the Pekhorka and Chechera Rivers with their inflows. Now the soil cover of the area of the reclaimed Kuchino solid waste landfill is significantly transformed by anthropogenic activity from agricultural use to the municipal solid waste landfill. In this regard the surface of a body of the ground is occupied by the soil of final overlapping. We considered the multicomponent and uneven-age composition of the solid waste in Kuchino and take into account an assessment of soils using the broadest set of controlled indicators: general sulfur, gross structure of compounds of sodium, magnesium, aluminum, phosphorus, potassium, calcium, titan, manganese, iron, lithium, beryllium, chrome, cobalt, nickel, copper, zinc, arsenic, strontium, molybdenum, cadmium, mercury, uranium, etc. (only 54 elements). The coefficient of maximum allowable concentration (CMAC) and coefficient of concentration (CC), a total indicator of concentration $(\mathrm{Zc})$ were criteria for evaluation in the analysis of polyelement pollution of soils heavy metals and metalloids of the current state of soils. Calculation of a total indicator of pollution of soils was carried out for a complex of all analyzed indicators, then separately - for priority pollutants I-III of classes of danger (in more detail in the technical report on carrying out engineering- 
ecological researches). As the second option of calculation higher $\mathrm{Zc}$ values were revealed, the general analysis of an ecological condition of soils was carried out according to the "worst" scenario. Thus, when determining the size Zc the list of the considered indicators was entered: cadmium, mercury, lead, zinc (danger class pollutants I), cobalt, nickel, molybdenum, copper, chrome (danger class pollutants II), barium, vanadium, tungsten and strontium (danger class pollutants III). Pollution of soils of strong and very strong degree was most significantly shown by concerning Cd (in total $-28 \%$ of the tested points) and $\mathrm{Pb}$ (in total $-10 \%$ of the tested points), it is traced at distance up to $600 \mathrm{~m}$ from ground borders in the southern and southeast direction on lines of the shortest geochemical drain to floodplains of the rivers. However at the same time strong extent of pollution of soils was noted only in single tests (for $\mathrm{Zn}$ and $\mathrm{Cu}$ ) or was not fixed in general (for $\mathrm{Ni}$ ). The analysis of the importance of polyelement pollution of soils of a zone of influence of Kuchino solid waste landfill showed that more than $50 \%$ of the surveyed points are characterized by the admissible level of total accumulation, dangerous category is noted in $8 \%$ of the tested positions, extra dangerous - in $37 \%$. Extremely dangerous category of complex pollution of soils heavy and rare metals is found only in the points of sampling dated for local decreases in a relief on lines of a geochemical drain from the ground towards the rivers.

Table 1. The general ecology-geochemical indicators of the soils in a zone of influence of Kuchino solid waste landfill.

\begin{tabular}{|c|c|c|c|c|c|c|}
\hline No. & $\begin{array}{c}\text { Indicators of maximum } \\
\text { allowable concentration }\end{array}$ & $\begin{array}{c}\text { thresh } \\
\text { old } \\
\text { limit } \\
\text { value }\end{array}$ & $\begin{array}{c}\text { Test 1k, } \\
\text { profile } \\
\text { III }\end{array}$ & $\begin{array}{c}\text { Test 2k, } \\
\text { profile } \\
\text { V }\end{array}$ & $\begin{array}{c}\text { Test 3k, } \\
\text { profile } \\
\text { VII }\end{array}$ & $\begin{array}{c}\text { Test 4k, } \\
\text { profile } \\
\text { I }\end{array}$ \\
\hline 1. & $\mathrm{pH}$ (water extract), unit & & 6.5 & 7.0 & 7.4 & 7.4 \\
\hline 2. & Exchange ammonium, mg/kg & & 7.2 & 2.5 & 3.6 & 2.2 \\
\hline 3. & Nitrates (on NO3), mg/kg & 130 & 169 & 77 & 83 & 99 \\
\hline 4. & Chloride ion, mg/kg & & 278 & 200 & 139 & 190 \\
\hline 5. & Sulfate ion, mg/kg - & & $<50.0$ & $<50.0$ & $<50.0$ & $<50.0$ \\
\hline 6. & Sulfur mobile, mg/kg & 160 & $<0.5$ & $<0.5$ & $<0.5$ & $<0.5$ \\
\hline 7. & Oil products, mg/kg & & 9.5 & 27.4 & 55.0 & 60.1 \\
\hline 8. & $3,4-$ benz (and) pyrene, mg/kg & 0,02 & $<0.005$ & $<0.005$ & $<0.005$ & $<0.005$ \\
\hline 9. & Phenols, mg/kg & & $<0.05$ & $<0.05$ & $<0.05$ & $<0.05$ \\
\hline 10. & Cadmium (gross form), mg/kg & 0,5 & 0.14 & 0.11 & 0.17 & 0.12 \\
\hline 11. & Copper (gross form), mg/kg & 33 & 6.5 & 13.4 & 10.3 & 10.8 \\
\hline 12. & Arsenic (gross form), mg/kg & 2 & 1.4 & 3.4 & 1.4 & 1.3 \\
\hline 13. & Nickel (gross form), mg/kg & & 4.02 & 8.1 & 9.4 & 6.7 \\
\hline 14. & Lead (gross form), mg/kg & 32 & 10.8 & 19.7 & 41.2 & 16.8 \\
\hline 15. & Zinc (gross form), mg/kg & 55 & 26.8 & 43.6 & 749.0 & 35.6 \\
\hline 16. & Mercury (mobile form), g/kg & & $<0.1$ & $<0.1$ & $<0.1$ & $<0.1$ \\
\hline 17. & Zinc (mobile form), mg/kg & 23 & 135 & 32 & 119 & 64 \\
\hline 18. & Copper (mobile form), mg/kg & 3 & 3.2 & 1.6 & 2.2 & 1.1 \\
\hline 19. & Cobalt (mobile form), mg/kg & 5 & 0.6 & 0.8 & 0.4 & 0.7 \\
\hline 20. & Manganese (mobile form), & 60 & 21.3 & 40.1 & 15.2 & 21.1 \\
\hline
\end{tabular}

Source: The project of recultivation of Kuchino solid waste landfill in the territory of the city district Balashikha of the Moscow region. Section 8 List of Actions for Environment Protection. Book 
1 Assessment of impact of a capital construction project on the environment. Code: 1747-RP-27.09.17 EIA. 2017.

Among heavy metals the cadmium is the leading element of pollution of soils. Its concentrations in points with dangerous and extremely dangerous categories of pollution are increased at 10-90 times in comparison with a background; in some cases there are the most active accumulation of $\mathrm{Ag}$ (up to 73), by $\mathrm{Hg}$ (up to 34), As (up to 28), Mo and $\mathrm{U}$ (up to 74) for $\mathrm{Zn}$ (up to 7). The range of pollutants with values of $\mathrm{Ks}>2$ is very wide (5-20 elements and more) that testifies to complex multicomponent structure of sources of pollution of soils. The general ecology-geochemical indicators of the soils in a zone of influence of Kuchino solid waste landfill are in Tab. 1.

In all tested points there is an increase in mobile forms of zinc size that testifies to high water and migratory abilities of this element.

\section{Conclusion}

The system of a beam drainage on solid waste landfill is one of possible ways of decrease in negative impact of heavy metals on the environment.

The device of system of a beam drainage is made for collecting a filtrate with a conclusion to treatment facilities of the filtrate which is most polluted by heavy metals. Purpose of a beam drainage - pumping of the ground waters polluted by a filtrate coming to water reception of wells from horizontal wells of a beam drainage. In compliance with the executed modeling of a hydrogeological situation in the project the system of the intercepting drainage which is turning on the device of 6 wells of the beam drainages and horizontal beam drains located along foundation of east and southern parties of an embankment of the ground. There should be also a pressure head waste collector for withdrawal of soil waters and filtrate on treatment facilities.

Thus, in the course of studying we found excess of concentration of heavy metals on the Kuchino landfill. One of optimum ways of decrease in their negative impact on the environment is construction of a beam drainage which will be able to clean the ground filtrate - the main sources of soil pollution.

The publication was prepared with the support of the "RUDN University program 5-100".

\section{References}

1. Heavy Metal Pollution in Soils from Anthropogenic Activities. LAP LAMBERT Academic Publishing, 120 (2011)

2. K. B. Mmlova, A. S. Likuku, G. K. Gaboutloeloe, African Journal of Environmental Science and Technology 5, 3, 186-196 (2011)

3. L. Grzebisz, J. Ciegla, J. Komisarek, J. Potarzycki, Polish Journal of Environmental Studies 11, 5, 493-499 (2002)

4. S. Dragović, N. Mihailović, B. Gajić, Chemosphere 74, 491-495 (2008)

5. G. V. Dobrovolsky, I. S. Urusevskaya, Geography of soils (MSU Publishing House, Publishing house "Colossus", 2004)

6. The project of recultivation of Kuchino solid waste landfill in the territory of the city district Balashikha of the Moscow region.Section 8 List of Actions for Environment Protection .Book 1 Assessment of impact of a capital construction project on the environment. Code: 1747-RP-27.09.17 EIA (2017) 
7. The conclusion by results of observations of state of environment on the site of placement of Kuchino solid waste landfill in 2016 (Balashikha district, Moscow region).

8. GN 2.1.7.2041-06 "The Maximum-permissible Concentration (MPC) of chemicals in to the soil".

9. GN 2.1.7.2511-09 "Approximate and Admissible Concentration (AAC) of chemical substances in the soil".

10. GOST 17.4.1.02. "Conservation. Soils. Classification of chemicals for pollution control"; 